\title{
DIFERENCIA Y DIALÉCTICA EN HEGEL
}

\section{DIFFERENCE AND DIALECTICS IN HEGEL}

\author{
Mauro JIMÉNEZ* \\ Universitat de València
}

\begin{abstract}
RESUMEN: En este artículo estudio la filosofía hegeliana. En particular, trato de enmarcar la doctrina del ser dentro de la Ciencia de la Lógica, y ésta a su vez dentro del sistema filosófico hegeliano para, finalmente, acabar reflexionando sobre la cuestión de la diferencia a partir de la categorización lógica hegeliana, siempre plegada al método dialéctico.

Palabras Clave: Dialéctica, Diferencia, Filosofía sistemática, Hermenéutica filosófica.

ABSTRACT: In this article I study the Hegelian philosophy. Especially, I try to frame the doctrine of the being inside the Science of the Logic, and this one inside the philosophical Hegelian system to end up by thinking about the question of the difference from the logical Hegelian categorization, always folded to the dialectical method.
\end{abstract}

KeYwords: Dialectics, Difference, systematic Philosophy, philosophical Hermeneutics.

Todo adentrarse en la filosofía hegeliana resulta una tentativa de comprensión en la que la ilusión de lo asido debe ir mucho más avanzada que el mismo comprender, porque su especulación se halla en la frontera de lo decible, o de otro modo y con ecos de Wittgenstein, en los límites del lenguaje. La modernidad filosófica ha utilizado la estolidez de su sistema, ya como contrafuerte para

* El autor pertenece a la Sociedad Española de Estudios de Nietzsche: SEDEN. 
el absolutismo, ya para lanzar hacia sus muros la crítica del individualismo, del subjetivismo, del existencialismo, del historicismo, y otros ismos que han ido poblando nuestra contemporaneidad.

La comprensión hegeliana establece por todo ello cierta fe hermenéutica, al igual que los versos de Góngora requieren una asidua visitación para hallar su sentido tras la belleza de la forma. Y no es mala comparación la del alemán Hegel con nuestro Góngora, ambos construyeron perfectos sistemas - filosófico y poético, respectivamente- cuyo andamiaje conceptual tenía la palabra como basamento fundamental. Sin embargo, este tipo de decir que aspira a la diana expresiva y a la perfección formal adolece en la monumentalidad de sus aristas de aquella claridad que Ortega tenía por la cortesía del filósofo. De ahí que muchos de sus críticos aborrezcan un decir tal pensando que tras él no habrá nada o lo que hay no merece tanto rebuscamiento. Así, por ejemplo, Schopenhauer y Nietzsche parodiaron la sistematicidad hegeliana. Pero no toda crítica a la expresión hegeliana merece un repudio, y muchos han sido quienes han reconocido la dificultad pero también han buscado tras ella su magma central con detenimiento, con paciencia, con tesón, y aun con cierta fe. En este sentido, el mismo Adorno, que tampoco posee una claridad excesiva, reconoce la dificultad hegeliana desde la admiración filosófica:

«Las resistencias que las grandes obras sistemáticas de Hegel, especialmente la Ciencia de la lógica, oponen a la comprensión son cualitativamente distintas de las que acompañan a otros textos malfamados. Pues la tarea no consiste simplemente en hacerse con un significado que sin lugar a dudas se encuentre en el texto, valiéndose de una atención exacta a éste y de cierto esfuerzo mental, sino que en muchos pasajes el sentido mismo es incierto, y hasta el momento ningún arte hermenéutica lo ha establecido incuestionablemente (sin lo cual no existen filología hegeliana ni crítica textual suficiente alguna). [...] En el terreno de la gran filosofía, Hegel es, ciertamente, el único con el cual de vez en cuando no se sabe, ni se puede averiguar de forma concluyente, de qué se está hablando, en definitiva, y con el cual no está garantizada ni siquiera la posibilidad de semejante averiguación» ${ }^{1}$.

1 Th. W. Adorno, Tres estudios sobre Hegel, Madrid, versión española de Víctor Sánchez de Zavala, Madrid, Taurus, 1991, pp. 119-120. 
Un hecho que imposibilita el acercamiento exento a una de las partes del sistema hegeliano estriba en que toda su filosofía, como la realidad efectiva ${ }^{2}$, es un todo compacto del que no puede extirparse un fragmento si no se ha comprendido el conjunto. Este sería el rasgo fundamental del absoluto hegeliano, su naturaleza compacta. Todos y cada uno de los instantes que configuran la realidad efectiva es insustituible e imborrable. Esto significa que lo real efectivo no permanece inmóvil como ya intuyera Heráclito, sino que se actualiza en un proceso de continuo movimiento, cuyas partes se desarrollan sucesivamente. Sin embargo, en esta progresión que configura la realidad efectiva lo positivo y dotador de sentido es el todo examinado desde su movimiento. Aceptando de entrada junto a Adorno la limitación que todo interpretar a Hegel implica trataré de llevar a cabo en estas líneas el siguiente despliegue: enmarcar la doctrina del ser dentro de la Ciencia de la Lógica, y ésta a su vez dentro del sistema filosófico hegeliano para finalmente acabar reflexionando sobre la cuestión de la diferencia a partir de la categorización lógica hegeliana siempre plegada al método dialéctico.

Pues bien, Hegel estructura su propia filosofía en la asunción del movimiento de lo real efectivo para su propia especulación. Así lo real y el espíritu o absoluto hegeliano participan del mismo proceso sucesivo; afirmación ésta que posibilita la comprensión de las siguientes líneas:

"Lo que es racional, eso es efectivamente real, y lo que es efectivamente real, eso es racional. Estas proposiciones tan sencillas han parecido escandalosas a muchos y se han ganado enemigos precisamente entre aquellos que no quieren renunciar a estar en posesión de la filosofía e incluso de la religión. Resulta innecesario traer aquí a colación a la religión, ya que estas proposiciones expresan con demasiada claridad las doctrinas religiosas sobre la divina providencia. Pero, por lo que se refiere a [la comprensión de] su sentido

2 Como señala Valls Plana en una importante nota de su edición de la Enciclopedia de Hegel, el filósofo alemán utiliza dos conceptos cercanos pero que no podemos confundir para evitar graves malentendidos hermenéuticos: Hegel habla de Realität y de Wirklichkeit, pero mientras que la primera designa la «realidad» el segundo lo hace a la «realidad efectiva». Esta diferenciación es fundamental para comprender la filosofía de Hegel como lo muestra el hecho de que tratara sobre ella en su Lógica. Para Hegel Wirklichkeit refiere a la única realidad que merece ser tenida por tal, esto es, una realidad fenoménica que no es un simple fenómeno, sino que en ella aparecen unidos tanto la apariencia como el concepto mostrando así lo racional su pleno sentido. Cfr. G. W. F. Hegel, Enciclopedia de las ciencia filosóficas, ed. de Ramón Valls Plana, p. 105. 
filosófico, hay que suponer mucha formación, es decir, es preciso saber no solamente que Dios es efectivamente real, que él es lo más efectivamente real y que sólo él lo es verdaderamente, sino que también es necesario saber, desde el punto de vista formal, que la existencia en general es en parte fenómeno y solamente en parte es realidad efectiva. En la vida común se denomina realidad a cualquier ocurrencia, al error, al mal y a todo lo que pertenece a este campo, así como a cualquier EXISTENCIA atrofiada y efímera se la llama precipitadamente realidad efectiva. Pero incluso para el sentir corriente, una EXISTENCIA contingente [o hecho casual] no merece el enfático nombre de realidad efectiva. Lo contingente es una existencia que no tiene más valor que el de una posibilidad, algo que tanto es como podría igualmente no sern ${ }^{3}$.

Lo real efectivo y lo espiritual se desenvuelven circularmente tal que el movimiento es el del especular en sí mismo. La reflexión hegeliana permite una distinción en tres momentos: $\alpha$ ) un primer estado del ser «en sí»; $\beta$ ) un segundo momento que actualiza el «ser otro» o "fuera de sí»; y $\gamma$ ) un tercer momento en el que el ser retorna a sí o "ser en sí y para sí»"

3 Ibid., pp. 106-107. Asimismo en su visión de la Historia Universal muestra la actualización de la razón en la realidad histórica: «[...] el único pensamiento que aporta [la filosofía] es el simple pensamiento de la razón, de que la razón rige el mundo y de que, por tanto, también la historia universal ha transcurrido racionalmente. Esta convicción y evidencia es un supuesto, con respecto a la historia como tal. [...] Es necesario llevar a la historia la fe y el pensamiento de que el mundo de la voluntad no está entregado al acaso. Damos por supuesto, como verdad, que en los acontecimientos de los pueblos domina un fin último, que en la historia universal hay una razón —no la razón de un sujeto particular, sino la razón divina y absoluta- L La demostración de esta verdad es el tratado de la historia universal misma, imagen y acto de la razón. Pero la verdadera demostración se halla más bien en el conocimiento de la razón misma. Esta se revela en la historia universal. La historia universal es solo la manifestación de esta única razón; es una de las figuras particulares en que la razón se revela; es una copia de ese modelo que se ofrece en un elemento especial, en los pueblos.», G. W. F. Hegel, Lecciones sobre la Filosofía de la Historia Universal, Madrid, Alianza, 2004, pp. 43-44.

${ }^{4}$ Sobre el carácter circular de la filosofía dice Hegel: «Cada parte de la filosofía es un todo filosófico, un círculo que se cierra en sí mismo, pero la idea filosófica se contiene allí [en las partes] bajo una determinidad particular o elemento. Y porque el círculo singular es en sí mismo totalidad, rompe también los límites de su elemento y funda una esfera ulterior. Por ello se presenta la totalidad como un círculo de círculos cada uno de los cuales es un momento necesario, de tal manera que el sistema de sus elementos propios constituye la idea total, la cual aparece también de este modo en cada círculo singular.», Ibid., pp. 117-118. 
En toda la filosofía de Hegel, como sucede claramente con la división de la Ciencia de la Lógica, es fundamental el número tres, siempre presente tanto en la dialéctica como en la estructuración de sus obras. El proceso triádico muestra un ritmo del devenir del ser en un en sí, un fuera de si y un para sí.

La traducción dialéctica del movimiento trino del ser a la realidad efectiva se realiza con la diferenciación entre «idea», «naturaleza» y "espíritu». La idea, que vendría a ser la racionalidad pura en su significado más propiamente idealista, tiene en sí la raíz de su devenir, según el cual en primer lugar acontece la objetivación mediante un proceso de alienación natural, para después superar de nuevo esa exteriorización para realizarse plenamente. Según este desarrollo, el espíritu se contempla a sí mismo merced a su asunción progresiva en la objetivación ${ }^{5}$.

Y si el espíritu se realiza en un despliegue triádico la filosofía que se ocupa de su estudio no puede ser menos. Consecuentemente, Hegel divide su filosofía en tres como establece en su Enciclopedia:

«I. La lógica, ciencia de la idea en sí y para sí.

«II. La filosofía de la naturaleza, como ciencia de la idea en su ser-otro.

«III. La filosofía del espiritu, como ciencia de la idea que regresa a sí desde su ser-otro" ${ }^{6}$.

La Ciencia de la lógica de Hegel ha sido considerada como una obra capital sobre todo a partir del siglo XX. Este hecho, más que a la fluctuante pleamar de

5 La historia de Europa sería la prueba hegeliana de la realización del Espíritu, como señala Diego Sánchez Meca: «En el pensamiento de Hegel, en concreto, Europa aparece como el lugar y el tiempo conceptual en el que se cumple el destino espiritual de la humanidad como expresión, realización y consumación del Espíritu o Razón universal y de la libertad. La dialéctica del Espíritu hace posible una determinación lógica e histórica de la identidad europea en conformidad con su origen, lo que le proporciona un fundamento interno de carácter ontológico. Europa, pues, es comprendida hegelianamente como la síntesis del origen consumado que nos espera como patria a la que retornamos tras la odisea, a través de la historia, de una conciencia ya muy enriquecida con la reapropiación y asimilación de todo lo diverso.», D. Sánchez Meca, El nihilismo, Madrid, Síntesis, p. 242.

${ }^{6}$ G. W. F. Hegel, Lecciones sobre la Filosofia de la Historia Universal, p. 121. 
las modas, se debe también a que en la lógica hegeliana el lenguaje posee una gran importancia, algo que sin duda no podía pasar desapercibido al giro lingüístico de la filosofía contemporánea. Sin embargo, posee la lógica hegeliana un cuerpo filosófico y una finalidad que rebasa su mera descripción lingüística. $\mathrm{Y}$ es que en Hegel antes que ninguna otra cosa la filosofía se observa desde el marco del sistema, luego la lógica sólo capta la idea como logos, idea que a continuación se desarrolla como naturaleza y espíritu. De este modo, y según la propia confesión hegeliana, la lógica configura una parte más de su sistema.

El cuerpo sistemático de su obra se descubre en la intuición primera del significado de la dialéctica en los Escritos de juventud, donde la dialéctica aparece actualizada a partir del estudio de la visión religiosa de griegos, judíos y cristianos. Así, la religión se opondría entre las actualizaciones griegas y judías, mientras que el cristianismo supondría la conciliación sintética de la oposición.

La clave de bóveda del edificio sistemático hegeliano es su radical idealismo abarcador del mundo entero: la realidad no es substancia, por lo que ésta y su verdad no pueden ser más que espíritu o pensamiento. A esta idea Hegel llega siguiendo las huellas de Descartes, Kant, Fichte y Schelling. Pero a diferencia del, en cierto modo, «idealismo estático» platónico, para Hegel esa realidad cuya verdad es idea, espíritu o pensamiento no se justifica desde el inmovilismo, sino desde el cambio heraclíteo, un cambio como actividad o proceso. Como indica Diego Sánchez Meca, en el pensamiento de Hegel la temporalidad queda sublimada por la filosofía en las diferentes determinaciones de la Idea, de modo que dentro del sistema el movimiento es el reconocimiento de las distintas formas de la Idea en su unidad:

«Hegel habla del movimiento de la Idea como de un movimiento de peregrinaje en el tiempo, en cuanto condición necesaria para su concreción. Sin embargo, este peregrinaje no es el que origina la presencia de la Idea para sí, por lo que, en rigor, no pueden coincidir historicidad y temporalidad. La historicidad, en cuanto totalizadora, es esencialmente contratemporal, o sea, movimiento de la Idea hacia su unidad en y a través — pero contra - el movimiento de peregrinación-exteriorización en el tiempo. Es por ello por lo que la misión de la historia de la filosofía — y lo que hace de ella una actividad filosófica de pleno derecho-, no será la descripción de los avatares de esa peregrinación, sino la determinación del regreso o del retorno hacia la uni- 
dad de la Idea en y a través de la dialéctica de la pluralidad de las filosofías. La historia de la filosofía no acontece, en definitiva, dirigida por el discurrir temporal, sino dirigida a la eternidad, o sea, hacia la presencia absoluta de la Idea a sí misma, en la síntesis concreta de todas sus determinaciones» ${ }^{7}$.

Así pues, la cuestión de la filosofía como sistema encuentra en Hegel una importancia fundamental, y no sólo porque él mismo se la otorgó, sino porque también buena parte de las críticas que sobre su especulación se han realizado se han basado sobre su pretensión de sistematicidad. Sobre este punto matiza Félix Duque:

«[...] gracias a los esfuerzos de la edición académica, así como de las lecciones y apuntes como preparación para éstas, ha quedado definitivamente en entredicho la imagen del pensador hipersistemático, que construyera sus doctrinas pieza a pieza como si de un juego de construcciones se tratase. El «sistema» aparece más bien como un desideratum, tras el cual se va como en pos de un principio regulativo (en el sentido kantiano) $»^{8}$.

Y este desideratum lo establece el mismo Hegel cuando habla sobre la forma de la filosofía en su Enciclopedia:

«El pensamiento libre y verdadero es en sí mismo concreto y de este modo es él idea y, en su total universalidad, la idea o lo absoluto. La ciencia de éste es esencialmente sistema, porque lo verdadero sólo es desarrollándose dentro de sí como concreto y tomándose y reteniéndose [todo] junto en unidad, es decir, sólo es como totalidad; y solamente mediante la diversificación y determinación de sus distinciones puede ser la necesidad de ellas y la libertad de todo»?

7 D. Sánchez Meca, Teoría del Conocimiento, Madrid, Dykinson, 2001, p. 324.

${ }^{8}$ F. Duque, Historia de la Filosofía Moderna. La era de la crítica, Madrid, Akal, 1998, p. 334.

9 G. W. F. Hegel, Enciclopedia de las ciencias filosóficas, op. cit., p. 117. En cuerpo de letra más pequeña y a continuación comenta Hegel el peligro de un filosofar no sistemático: «Un filosofar sin sistema no puede ser nada científico; por lo demás, porque tal modo de filosofar expresa de suyo más bien un modo subjetivo de sentir, es él contingente según su contenido. Un contenido sólo se justifica como momento del todo; fuera de éste es una suposición infundada o certeza subjetiva; muchos escritos filosóficos se limitan así a expresar solamente pareceres y opiniones. Erróneamente se entiende por sistema una filosofía con un principio limitado, distinto de otros; por el contrario, es principio de verdadera filosofía contener dentro de sí todos los principios particulares.», Ibidem. 
Hegel, como indica Félix Duque, trata de responder con el despliegue de su filosofía al problema con el que se encontraron Spinoza y Kant, y de la metafísica moderna en fin, que no es otro que la conciliación entre libertad y necesi$\operatorname{dad}^{10}$. El joven Hegel presenta la religión como espacio por excelencia donde poder salvar la distancia entre la subjetividad y la objetividad desplegada. En la religión el espíritu finito comprende el dictado del espíritu divino que cifra su sentido en la abnegación y el sacrificio de la naturaleza. El salto acometido en este punto por Hegel estriba en convertir el espíritu divino en espíritu absoluto y superar el problema de la infinitud no resuelto por Fichte.

La filosofía de Hegel no observa en la realidad substancias sino el despliegue del espíritu, del raciocinio del sujeto. Aquí Hegel continúa la senda incoada por el ich denke kantiano. Desde este punto de vista, afirmar que la realidad no es producto sino pensamiento significa decir que la realidad es actividad. El sujeto para conocerse necesita acotarse, poner un límite a su ser, frontera que una vez alcanzada trata de rebasar en un proceso de continuo dinamismo. Según Hegel, en este proceso ya atisbado por Fichte existe el peligro de caer en la mala infinitud o infinito malo, esto es, el límite es continuamente superado y negado sin que exista una reconciliación entre el ser y el no ser. La posición de Hegel resuelve la cuestión subsumiendo la finitud dentro de lo infinito. Así, la existencia de la finitud para el sujeto es imprescindible para tomar conciencia de sí, pero esa finitud en realidad no existe más que en un constante proceso de infinitud elaborado a base de negación de la infinitud y negación de la negación de la infinitud. Lo finito desde esta perspectiva no existe sino como parte de un proceso en el que se atisba la infinitud. La dinámica queda de este modo expresa en un sistema donde lo individual está inserto en lo universal y éste en sus sucesivas negaciones. Es importante comprender que toda la realidad se configura en este proceso de finitud/infinitud, y como no podía ser menos el mismo sistema hegeliano se estructura en ese movimiento dinámico de actualización del espíritu.

La idea de lógica poseía hasta Hegel un sentido bien distinto del que él construyó en su monumental Ciencia de la Lógica, y aunque también cupiera decir que no existía un significado unívoco de lo que se entendía por «lógica», sin

${ }^{10}$ F. Duque, Historia de la Filosofía Moderna. La era de la crítica, op. cit., p. 338. 
embargo sí que se podía afirmar que no era nada parecido a lo que pretendía el de Stuttgart. Desde las reflexiones aristotélicas sobre las reglas del pensamiento abstracto y de la argumentación se había ido elaborando un cuerpo filosófico que respondía al epígrafe de lógica y que vendría a situarse en lo que en nuestros días conocemos como lógica formal o lógica simbólica. Bajo tal acepción se suele entender la ciencia que estudia las reglas del razonamiento visto éste desde una perspectiva abstracta, esto es, el razonamiento en sí mismo exento de cualquier contenido argumental concreto. En este sentido, la lógica estudia el razonamiento correcto desde un punto de vista formal. En líneas generales Aristóteles había desarrollado la investigación lógica sobre los silogismos en los Analíticos posteriores señalando que la verdadera ciencia debía desarrollarse a partir de la derivación silogística correcta de las observaciones empíricas en busca de leyes universales. El Estagirita afirmó que el paradigma de demostración científica era el silogismo Bárbara ${ }^{11}$ :

\section{Todos los $M$ son $P$. \\ Todos los $S$ son $M$. \\ Todos los $S$ son $P$.}

Así pues, históricamente la lógica se había desarrollado en unos parámetros y con unos objetivos bien distintos de los que Hegel quiso desarrollar bajo su acepción. Será conveniente observar qué es lo que pensaba Hegel al respecto de la evolución histórica de la filosofía:

«Por una parte, la historia de la filosofía muestra en las diversas filosofías que van apareciendo una sola filosofía con diversos peldaños de formación $\mathrm{y}$, por otra parte, muestra que los principios particulares, uno de los cuales subyace en cada una de las filosofías, son solamente ramas de uno y el mismo todo. La última filosofía según el tiempo es el resultado de todas las filosofías anteriores y ha de contener por ello los principios de todas; por esta razón, aunque es filosofía de otra manera, es la más desarrollada, la más rica y la más concreta» ${ }^{12}$.

${ }_{11}$ Cfr. J. Losee, Introducción histórica a la filosofía de la ciencia, Madrid, Alianza, 2001, p. 18.

12 G. W. F. Hegel, Enciclopedia de las ciencias filosóficas, op. cit., p. 116. 
Tras estas líneas cabe preguntarse ¿cuál fue la filosofía con la que se encontró Hegel antes de su especulación? ¿qué última filosofía daba sentido a la historia del pensar? La respuesta en este punto se encuentra en Kant. Sin el criticismo kantiano no se entiende ni el idealismo alemán ni el sistema hegeliano, que a su vez trata de superar a ambos. Por lo tanto será necesario observar cuál era el tratamiento que Kant había otorgado a la lógica en su filosofía para a continuación analizar los avances hegelianos.

En el marco de su Crítica de la razón pura, concretamente en la segunda parte de la Doctrina trascendental de los elementos, habló Kant de la lógica trascendental. Por ella entendía el de Königsberg la ciencia del entendimiento puro y del conocimiento de razón por el cual pensamos objetos completamente a priori, o con sus palabras:

«Con la esperanza, pues, de que haya tal vez conceptos que se refieran $a$ priori a objetos, no en cuanto intuiciones puras o sensibles, sino simplemente en cuanto actos del entendimiento puro - actos que son, por tanto, conceptos, pero de origen no empírico ni estético-, nos hacemos de antemano la idea de una ciencia del conocimiento puro intelectual y racional, un conocimiento a través del cual pensamos los objetos plenamente a priori. Semejante ciencia, que determinaría el origen, la amplitud y la validez objetiva de esos conocimientos, tendría que llamarse lógica trascendental, ya que sólo se ocupa de las leyes del entendimiento y de la razón, si bien únicamente en la medida en que tales leyes se refieren a objetos a priori, a diferencia de lo que hace la lógica general, que se refiere indistintamente a conocimientos racionales, tanto empíricos como puros» ${ }^{13}$.

De este modo, lo que diferencia la lógica trascendental kantiana de la secular lógica filosófica es que aquélla encuentra su campo de acción en la existencia de conceptos puros a priori. Estos conceptos puros a priori serían la materia de la lógica trascendental a la vez que los esquemas de pensamiento según los cuales la razón moldearía la realidad captada mediante la intuición sensible. Hegel, pues, se encuentra con la lógica trascendental kantiana como el último y más importante tratamiento que desde la filosofía se había operado en la lógica; y

13 I. Kant, Crítica de la razón pura, Madrid, Alfaguara, 2002, pp. 99-100. 
consecuente con su visión de la historia de la filosofía no se atiene a ella sino que asumiéndola trata de superarla desde su propia concepción especulativa ${ }^{14}$.

En efecto, Hegel entenderá la lógica, al igual que Kant, la ciencia de las determinaciones puras del pensamiento, pero no las verá como formas vacías, sino como substancia universal de la realidad efectiva y como proceso que une contenido y forma. A diferencia de Kant, Hegel incardina en la ciencia de la lógica la realidad fundamentalmente porque desde su sistema lo racional forma parte de la realidad efectiva y a la inversa. Veamos como en las siguientes líneas el de Stuttgart acaso critique implícitamente la posición kantiana al respecto de la lógica:

«Hasta ahora el concepto de lógica se fundaba sobre la separación dada de una vez para siempre en la conciencia ordinaria, del contenido del conocimiento y de la forma de éste, es decir, en la separación de la verdad y la certeza. Se presupone ante todo que la materia del conocimiento existe como un mundo acabado, en sí y por sí, fuera del pensamiento; que el pensamiento por sí es vacío y que se añade como una forma extrínseca a aquella materia, se llena de ella, y solamente entonces adquiere un contenido y se convierte así en conocimiento real $»^{15}$.

Como vemos para Hegel la filosofía anterior a él no ha sido capaz de superar la contradicción entre forma y contenido en el ámbito de la lógica. Sin embar-

14 «Kant por otro lado aprecia la lógica, es decir el conjunto de determinaciones y principios que en el sentido habitual se llama lógica, como afortunada, por haber ella logrado, antes que las otras ciencias, un acabamiento tan precoz. Desde Aristóteles la lógica no ha retrocedido pero tampoco avanzó un paso; esto último ocurrió porque, según todas las apariencias, parece acabada y completa. Pero si desde Aristóteles en la lógica no se han efectuado modificaciones —en efecto, las modificaciones, como se ve si se observan los modernos compendios de lógica, consisten a menudo sólo en eliminaciones-, esto lleva más bien a la conclusión de que esta ciencia necesita con mayor razón una reelaboración total; pues una labor del espíritu continuada, durante 2000 años, debe haberle proporcionado una conciencia más elevada en torno a su pensamiento y a su pura esencia en sí misma. La comparación entre las formas a que se han elevado el espíritu del mundo práctico y religioso y el espíritu de la ciencia en cualquier clase de conciencia, real o ideal, y la forma en que se encuentra la lógica, que es la conciencia de la esencia pura del espíritu, demuestra diferencias demasiado grandes para que no resulte con evidencia inmediata, aun a la observación más superficial, que esta última conciencia es en absoluto desproporcionada respecto a dichas elevaciones e indigna de ellas.», G. W. F. Hegel, Ciencia de la lógica, Buenos Aires, Ediciones Solar, p. 48.

15 Ibid., p. 42. 
go, a partir de su concepción de la dialéctica es posible conseguir una asunción positiva de los opuestos según la cual el esquematismo de la especulación y el darse de la realidad efectiva coincidan en la positividad del concepto, el cual es al mismo tiempo razón y realidad efectiva. El saber absoluto, entonces, es la propuesta hegeliana capaz de salvar la división entre sujeto y objeto. La ciencia filosófica en tanto que ciencia pura de la idea contiene «el pensamiento, en cuanto éste es también la cosa en sí misma, o bien contiene la cosa en sí, en cuanto ésta es también el pensamiento puro». Y la verdad que la ciencia obtendría sería la conciencia de sí mismo que se actualiza mediante el concepto, esto es, "que lo existente en si y por si es concepto consciente, pero que el concepto como tal es lo existente en si y para sì ${ }^{16}$. Como se ve la asunción de la forma y del contenido de la ciencia aparece posibilitada en la filosofía hegeliana merced al concepto cuya contenido es lo verdadero absoluto expresado no desde la exterioridad ya que la misma materia configura el pensamiento puro y consecuentemente la forma absoluta. Esta argumentación lleva a Hegel a señalar cuál es la naturaleza de la lógica:

«De acuerdo con esto la lógica tiene que ser concebida como el sistema de la razón pura, como el reino del pensamiento puro. Este reino es la verdad tal como está en sí y por sí, representación de Dios, tal como está en su ser eterno, antes de la creación de la naturaleza y de un espiritu infinito» ${ }^{17}$.

La lógica se encuentra como saber inmediato con Dios, según Hegel, diferenciándose del saber mediado que se ocuparía de los contenidos finitos. La razón pura que se despliegue en la lógica es para el de Sttutgart la certidumbre humana de la existencia de Dios, que es entendido aquí como lo infinito, lo eterno, el ente supremo, y que encuentra en la conciencia su certeza ${ }^{18}$.

16 Ibid., p. 46.

17 Ibid., p. 47.

18 Es conveniente recordar cuáles eran las definiciones de causa sui y de Dios que Spinoza realiza en su Ética: «Por causa de sí entiendo aquello cuya esencia implica la existencia, o, lo que es lo mismo, aquello cuya naturaleza sólo puede concebirse como existente»; y «Por Dios entiendo un ser absolutamente infinito, esto es, una substancia que consta de infinitos atributos, cada uno de los cuales expresa una esencia eterna e infinita. / Explicación: Digo absolutamente infinito, y no en su género; pues de aquello que es meramente infinito en su género podemos negar infinitos atributos, mientras que a la esencia de lo que es absolutamente infinito pertenece todo cuanto expresa su esencia, y no implica negación alguna», B. Spinoza, Ética, Madrid, Alianza, pp. 45 y 47, respectivamente. 
El pensamiento del que se ocupa la lógica hegeliana no versa sobre un asunto o sobre una materia determinada al que le daría base o esquema argumental, no es comparable a formas lógicas exentas de contenido que validarían lógicamente su certidumbre; ahora más bien las misma formas necesarias y sus propias determinaciones configuran el contenido, constituyendo así la verdad absoluta. El mismo Hegel reconoce que para comprender esta lógica hay que abandonar la creencia en la verdad como un hecho palpable o transferible a un mundo otro como hiciera Platón con el mundo de las Ideas. En Hegel la realidad efectiva de la cosa radica en el concepto, en él adquiere verdadera realidad y comprensión, siendo nula cuando es diversa de su concepto, abandonando así el ámbito de lo real efectivo para anclarse por lo tanto en lo contingente. Como se ve, pensamiento y existencia objetiva se implican:

"Pensar" es una expresión que aplica con preferencia a la conciencia la determinación contenida en ella. Pero, cuando se dice que existen en el mundo objetivo intelecto y razón, que el espíritu y la naturaleza tienen leyes universales, según las cuales se realizan su vida y modificaciones, se acepta que las determinaciones del pensamiento tienen asimismo valor y existencia objetivos» $^{19}$.

El paso que consecuentemente debe operar la filosofía hegeliana es la de convertir la lógica en metafísica ya que ambas se ocupan de los mismos objetos. Mediante la reflexión el yo descubre la verdadera naturaleza de la cosa, y así se revela ésta como producto de aquélla. Hasta Hegel la lógica era un órgano del pensamiento o una técnica secular del pensar correcto según unas formas determinadas, pero con el de Stuttgart la lógica da el paso de lo figural a lo ontológico. La lógica, al ser una determinación propia del pensamiento, no es puramente un esquema trascendental como señalara Kant, sino que se descubre como ontológico porque descubre las determinaciones esenciales de las cosas. Para Hegel aquí no hay separación entre forma y contenido. La lectura que del criticismo realiza Hegel observa como la filosofía crítica investiga los conceptos del entendimiento que utiliza la metafísica desde la oposición entre subjetividad y objetividad a partir de la experiencia. Esta dicotomía del criticismo lleva a sajar la realidad en dos polos de imposible reconciliación: la subjetividad y la cosa-en-sí. Y

19 G. W. F. Hegel, Ciencia de la lógica, op. cit., p. 47. 
en este contexto las categorías del pensar puro representarían los elementos subjetivos de la lógica kantiana criticados por Hegel al presentarse como conceptos vacíos a la espera de su relleno sensible o empírico. Las categorías otorgan a la experiencia de objetividad, pero por sí mismas las categorías descansan vacías en la conciencia subjetiva, de modo que sólo consiguen aplicarse con éxito y utilidad a partir de la experiencia. El enfrentamiento entre subjetividad y objetividad arroja como resultado la incapacidad del entendimiento de conocer la cosa-en-sí. Las categorías de la lógica trascendental kantiana son entonces determinaciones hueras a expensas de la percepción sensible, y por tanto incapaces de conseguir una determinación de lo absoluto. El paso hacia el absoluto no lo da la filosofía crítica porque aquél no se halla en la percepción, de modo que sobre él no se puede hablar desde la ciencia. El pensar y el existir encuentran en la filosofía kantiana una compartimentación estanca tan solo conectados cuando a las categorías del entendimiento se les proporciona material empírico, sin que por ello todo lo racional puro sea justificado salvo que encuentre existencia empírica. Mientras que en Kant la determinidad del pensar depende del mundo fáctico, para Hegel es el mismo pensar puro el que fundamenta su existencia mediante el proceso dialéctico. Así las cosas, Kant construye, según Hegel, una crítica del conocimiento, y no como él una filosofía del infinito o del absoluto ${ }^{20}$. Sucede que quizá Hegel reprocha a la filosofía de Kant precisamente lo que ella trata de evitar, ya que ésta se construye sobre la base de los enfrentamientos históricos entre la filosofía racionalista y la filosofía empirista. Desde este punto de vista su concepción de la lógica carece del absolutismo del idealismo hegeliano al mismo tiempo que desecha elementos que caracterizan el empirismo escéptico. Acaso no halla mejor explicación de la actitud kantiana que unas líneas del comienzo de la lógica trascendental en las que podemos apreciar cómo se rehuye a toda costa hacer depender la filosofía sólo de la razón o sólo de la sensibilidad empírica, así Kant aparece como el pensador de la síntesis:

20 «[...] la determinidad queda para el pensar como algo exterior; el pensar se queda sólo y simplemente en pensar abstracto, al cual aquí [en este punto de la filosofía kantiana] se le llama siempre razón. Ésta (y con ello llegamos al resultado) no proporciona más que la unidad formal para simplificar y sistematizar la experiencia; es un canon y no un organon de la verdad, no puede proporcionar una doctrina de lo infinito, sino solamente una crítica del conocimiento. Esta crítica consiste, en su último análisis, en la aseveración de que el pensar sólo es en sí mismo la unidad indeterminada y la actividad de esta indeterminada unidad», G. W. F. Hegel, Enciclopedia de las ciencias filosóficas, op. cit., pp. 156-157. 
«Si llamamos sensibilidad a la receptividad que nuestro psiquismo posee, siempre que sea afectado de alguna manera, en orden a recibir representaciones, llamaremos entendimiento a la capacidad de producirlas por sí mismo, es decir, a la espontaneidad del conocimiento. Nuestra naturaleza conlleva el que la intuición sólo pueda ser sensible, es decir, que no contenga sino el modo según el cual somos afectados por objetos. La capacidad de pensar el objeto de la intuición es, en cambio, el entendimiento. Ninguna de estas propiedades es preferible a la otra: sin sensibilidad ningún objeto nos sería dado y, sin entendimiento, ninguno sería pensado. Los pensamientos sin contenido son vacíos; las intuiciones sin conceptos son ciegas. Por ello es tan necesario hacer sensibles los conceptos (es decir, añadirles el objeto en la intuición) como hacer inteligibles las intuiciones (es decir, someterlas a conceptos). Las dos facultades o capacidades no pueden intercambiar sus funciones. Ni el entendimiento puede intuir nada, ni los sentidos pueden pensar nada. El conocimiento únicamente puede surgir de la unión de ambos» ${ }^{21}$.

Hegel cree superar el estado de la filosofía anterior sobre todo gracias a su método dialéctico, método al que se pliega toda la exposición sistemática de su especulación porque él mismo es el modo de actualizarse la razón en el mundo, esto es, la dialéctica para Hegel no es solamente una herramienta de mera justificación filosófica, sino que también la misma realidad efectiva reconoce en la dialéctica el desplegarse del espíritu absoluto. La lógica al igual que el sistema entero dentro del cual se incardina como una parte más posee un método de desarrollo que es también el mismo que el resto de secciones de la ciencia filosófica. Éste no es otro que la dialéctica, único método de progreso científico que caracteriza en su Ciencia de la Lógica:

«La única manera de lograr el progreso cientifico - y cuya sencillísima inteligencia merece nuestra esencial preocupación - es el reconocimiento de la proposición lógica, que afirma que lo negativo es a la vez positivo, o que lo contradictorio no se resuelve en un cero, en una nada abstracta, sino sólo esencialmente en la negación de su contenido particular; es decir, que tal negación, no es cualquier negación, sino la negación de aquella cosa determinada, que se resuelve, y por eso es una negación determinada. Por consi-

${ }^{21}$ I. Kant, Crítica de la razón pura, op. cit., A 51, B 75, p. 93. 
guiente en el resultado está contenido esencialmente aquello de lo cual resulta; lo que en realidad es una tautología, porque de otro modo sería un inmediato, no un resultado. Al mismo tiempo que la resultante, es decir, la negación, es una negación determinada, tiene un contenido. Es un nuevo concepto, pero un concepto superior, más rico que el precedente; porque se ha enriquecido con la negación de dicho concepto precedente o sea con su contrario; en consecuencia lo contiene, pero contiene algo más que él, y es la unidad de sí mismo y de su contrario. Por este procedimiento ha de formarse, en general, el sistema de los conceptos, y completarse por un curso incesante, puro, sin introducir nada del exterior ${ }^{22}$.

En la división de la lógica al igual que en la filosofía de la naturaleza y en la filosofía del espíritu, lo lógico-real es estructurado en los tres pasos correspondientes a la dialéctica: un primer paso abstracto y por ello propio del entendimiento; un segundo paso racional-negativo y consecuentemente dialéctico; y por último un tercer paso especulativo de asunción racional-positivo. La primera parte corresponde a la doctrina del ser, la segunda a la doctrina de la esencia, y la tercera a la doctrina del concepto y de la idea. En puridad, la lógica es la doctrina del pensamiento que se autoconoce reflexivamente yendo desde su inmediatez hasta su reflexión para regresar teniendo conocimiento en y para sí. De este modo, la doctrina del ser vendría a ser el descubrimiento en su inmediatez del concepto en sí; la doctrina de la esencia sería la reflexión y mediación del concepto como ser-para-sí; y finalmente la doctrina del concepto confirmaría el regreso a sí del concepto en sí y para sí.

En el desarrollo del sistema filosófico hegeliano la lógica se encuentra como primer momento antes de la filosofía de la naturaleza y la filosofía del espíritu. Pero hay que tener en cuenta que su desarrollo es circular, de modo que la lógica incoa su saber allí donde la filosofía del espíritu había arribado, lugar éste que no es otro que el saber absoluto, concepto o idea. Hegel publicó antes la Fenomenología del Espiritu (1807) que la Ciencia de la Lógica (1812-16), y por ello en las últimas páginas de aquélla encontramos el inicio del comienzo de ésta:

«En el saber cierra, pues, el espíritu el movimiento de su configurarse en cuanto ese configurarse viene lastrado por una no superada diferencia de la

22 Ibid., p. 50. 
conciencia. El espíritu ha cobrado el elemento puro de su existencia, es decir, el concepto. El contenido es aquí (en lo que respecta a la libertad de su ser o en lo que respecta a la autonomía que ese contenido ofrece), el contenido digo, en lo que respecta a esa su autonomía, no es sino el self que se enajena a sí mismo, o la unidad inmediata del saberse. El movimiento puro de esta enajenación, considerando esa enajenación en su contenido, constituye la necesidad de ese contenido. El contenido diverso, en cuanto contenido determinado, sólo lo es en la relación, pero no en sí, y su inquiescencia es la de suprimirse y superarse, o lo que es lo mismo: la negatividad; por tanto, la necesidad (o la diversidad), lo mismo que el ser igualmente self, y en esta forma sélfica en la que la existencia es inmediatamente pensamiento, es en la que el contenido es concepto» ${ }^{23}$.

Cuando el espíritu piensa el concepto ya se encuentra en el ámbito de la ciencia. En esta ciencia, que para Hegel concuerda con la lógica y con la metafísica, los conceptos aparecen determinados y ya no se está ante determinadas figuras que alcanza la conciencia. En la primera parte de la lógica, en la doctrina del ser, el pensamiento como razón o entendimiento descubre en la inmediación de su especulación las determinaciones fijas del ser, que así contempladas resultan distintivas entre sí. El resto de la lógica hegeliana tratará de superar esa rigidez primera mediante el proceso dialéctico para terminar volviendo de nuevo al comienzo de un modo circular. De este modo, en la misma lógica el ser deviene conocimiento de sí, esto es, en ella misma se da el proceder dialéctico.

Mientras que Kant comenzó la tabla de las categorías con las de cantidad primero y luego con las de la cualidad para seguir con las de la relación y por último con las de modalidad ${ }^{24}$; Hegel inicia la primera parte de la lógica, la doctrina del ser, con la determinidad o cualidad, después con la magnitud o cantidad, y finalmente con la medida. Cada una de estas secciones se encuentra dividida a su vez en tres, así en la determinidad-cualidad distingue Hegel: 1. Ser, 2. Existir, 3. Ser-para-sí; en la magnitud-cantidad: 1. Cantidad, 2. Cuanto, 3. Relación Cuantitativa; y por último en la medida: 1 . Cantidad específica, 2. Relación de masas subsistentes, 3. Devenir de la esencia.

${ }^{23}$ G. W. F. Hegel, Fenomenología del Espiritu, estudio introductorio, traducción y notas de Manuel Jiménez Redondo, Valencia, Editoria Pre-textos, 2006, pp. 909-910.

${ }^{24}$ I. Kant, Crítica de la razón pura, op. cit., p. 113. 
Todo el edificio especulativo de la ciencia de la lógica que yergue Hegel es un devenir dialéctico a través de las diferencias, y sin embargo en la mayoría de las filosofías actuales se le tiene como el mayor filósofo dogmático aniquilador de la diferencia en base a la última identidad. Es ineludible afirmar que la liberación de la diferencia en la filosofía contemporánea responde a menudo a un enfrentamiento con la filosofía dogmática de pensadores como Platón o Hegel, que suelen ser leídos como grandes metafísicos de la totalidad en detrimento de la individualidad o del sujeto, que en ese contexto queda anulado bajo el concepto, es decir, bajo la idea, el espíritu objetivado o razón. En buena medida toda la filosofía moderna se debate en torno la superación de Hegel, así leemos la obra de Kierkergaard, la de Nietzsche, e incluso, en una paradójico rechazo de Hegel a través de Marx, en la obra de los frankfurtianos más destacados, Adorno y Horkheimer. En este sentido, podríamos afirmar que el pensamiento de la diferencia establece una oposición con la filosofía hegeliana. La cuestión radica, en principio, en atisbar la identidad y el problema de lo mismo en el despliegue del tiempo descubriendo, entonces, la repetición, la diferencia, la copia, y el simulacro. La lógica de la identidad se verá rechazada por todos aquellos que eviten la identificación con el todo, encumbrando en su oposición la contradicción como elemento constitutivo del ser del ente ${ }^{25}$.

En los orígenes el problema de la diferencia aparecía cuando se trataba el dilema del cambio en el ser ${ }^{26}$. Parménides había establecido un abismo entre el ser y el no-ser, de forma que el cambio quedaba como un asunto engañoso propio del terreno del no-ser y objeto de las habladurías de la opinión. El ser, para Parménides, queda configurado como un todo inmutable. Heráclito introduce, en oposición al estatismo parmenídeo, la verdad del cambio como única realidad, así, el ser no sería algo inmóvil, sino plena movilidad, entera oscilación continua. Pero, ¿cómo hemos de llamar entonces a eso que no es y no es no-ser y es pleno cambio?, ¿es acaso el ser cambio como continua dialéctica entre ser y no-ser? Parece claro que la afirmación de la diferencia implica la afirmación del

${ }^{25}$ La presencia del psicoanálisis en el desarrollo del pensamiento de la diferencia es una consecuencia de su descubrimiento de fuerzas inconscientes capaces de alterar cualquier interpretación coherente del comportamiento humano, o de otro modo, que bajo la razón se oculta la contradicción.

26 Á. Gabilondo, La vuelta del otro. Diferencia, identidad y alteridad, Madrid, Trotta / Universidad Autonoma, pp. 17-51. 
no-ser, y, consecuentemente, la asunción de la existencia del no-ser. El no-ser, ahora, vendría a ocupar el lugar de la diferencia, porque refiere la diferencia del ser, algo que difiere del ser, y que no existe bajo su amparo sino en su diferencia, cuya existencia da muestra el cambio.

La idea de lo mismo aparece cuando Parménides identifica pensar con ser. La interpretación subjetiva de este hecho se da cuando colegimos que como el pensamiento no puede darse más que en el sujeto, ser y pensar devienen parejos en suerte de una metonimia existencial. La lectura idealista, sin embargo, puede ser rebajada con el requerimiento de la presencia que acontece en el pensamiento, esto es, el pensamiento tiene lugar en la cita de la presencia, del percibir, de ahí que el pensamiento rodee al ser en la presencia, y de un modo armónico, sólo se dé el pensamiento en el ser. Lo decisivo radicaría en el hecho de que la presencia convoca el pensamiento en el ser operando una apertura hacia el contorno y, así, una superación del solipsismo. Esto es esencial en la reflexión de la diferencia a partir de la cuestión del otro, si bien la crítica derridiana a la fenomenología vendrá precisamente al indicar cómo ésta promociona la presencia e ignora la cuestión de la huella y el diferir del signo.

La totalidad del ser en Heráclito quedaba configurada con la conexión entre ser y no-ser, pues el cambio distancia tanto como conecta estos dos polos de la existencia, reclamando la diferencia, podría defenderse, como verdadero estatuto existencial: un continuo ser diferente a través del devenir. En Heráclito el momento de la negatividad se torna positivo gracias a la diferencia, y aceptados así los conceptos de no-ser y ser el devenir resulta lo real. Esta realidad, no obstante, no se muestra rígida de antemano en aras de una necesidad absoluta, el azar sólo sostiene sobre su base la necesidad, de ahí que el decir (el $\lambda \delta$ jo $\zeta$ de Heráclito) sea el reino de la posibilidad, pero sólo la necesidad se deriva del azar, de la suma de la tirada de dados, como indicarán mucho después tanto Nietzsche como Deleuze.

Sobre el concepto de diferencia en Hegel es necesaria cierta cautela ante la común referencia a su sistema como dogmático: en Hegel hay muchos Hegel. Así, por ejemplo, en la Ciencia de la Lógica la configuración del ser del ente es imposible sin su confrontación con el límite (Grenze) y con el otro (Anderes). Además, el reconocimiento de la determinación o destino (Bestimmung) y la determinidad entitiva (seiende Bestimmheit) no se explican sin la necesaria con- 
sideración de la diferencia ontológica. Y sin embargo, el sistema al asumir la individualidad en la idea, absoluto o razón provoca su interpretación dogmática.

Quizás pueda decirse que paradójicamente no hay pensador más consciente de la diferencia ontológica que el mismo Hegel. Y digo de forma paradójica porque en él la diferencia, la distinción, la contradicción es un elemento ineluctable para el movimiento procesal de su sistema. El método que el de Stuttgart establece como el propio de la ciencia y que configura la máxima novedad de su perspectiva filosófica no es otro que la dialéctica, y ésta lleva en sí gracias a la negación la conciencia diferencial. No obstante, y esto es lo que vendría a aportar la dialéctica hegeliana, el tercer paso identificado como propiamente especulativo actualizaría la unificación de los contrarios. En este punto la gran cuestión para discernir el dogmatismo de la diferencia hegeliana sería si en la asunción última de los opuestos éstos son unificados bajo el espíritu o la idea sin que por ello las diferencias sean difuminadas, o lo que es lo mismo, si bajo el paraguas sistemático que Hegel construye y que alcanza en el concepto el saber absoluto cabe encontrar conservadas las diferencias ontológicas como elementos de la realidad efectiva. Estimo que una respuesta positiva no sólo es posible sino que una lectura detenida de Hegel llevaría a su aceptación. El problema de nuevo está en que incluso en ese caso la diferencia estaría asumida bajo la identidad última del concepto.

Así, cuando Hegel comienza su doctrina de la esencia halla en el ser la inmediación indeterminada del que sólo se puede predicar que «no tiene ninguna diferencia, ni en su interior ni hacia lo exterior. Por vía de alguna determinación o contenido, que se diferenciara en él, o por cuyo medio fuese puesto como diferencia de otro, no sería conservado en su pureza. Es la pura indeterminación y el puro vacío" ${ }^{27}$. De nuevo contradictoriamente el ser sería el rico yermo donde luego desfilarán las distintas determinaciones que compondrían la existencia, pero para eso antes es necesario la confrontación del ser con la nada. Sin embargo, entre el ser y la nada en un primer momento Hegel más que indicar diferencias subraya afinidades, coincidiendo ambas en la pura abstracción, que en el caso de la nada se torna negativa pero que no obsta para trabar unidad con el ser: «La nada en cuanto es esto inmediato, igual a sí mismo, es también inversamente

27 G. W. F., Ciencia de la Lógica, op. cit., p. 77. 
lo mismo que el ser. La verdad del ser, así como la de la nada, es, por consiguiente, la unidad de ambos; esta unidad es el devenin ${ }^{28}$. En Hegel existe un movimiento que va a la diferencia desde la unidad, identidad a la que finalmente volverá cuando se recorra todo el sistema. ¿Cuál es entonces la clave que configura la dialéctica entre identidad y diferencia en la lógica hegeliana? Acaso la clave resida precisamente en la historicidad de su filosofía, tiempo en el que como señala Félix Duque el nihilismo todavía no había arrasado con la idea de unidad ${ }^{29}$. La unidad hegeliana al abarcar y cobijar en su interior la diferencia no sólo desarrolla el devenir merced a ésta sino que vincula su propia justificación en la existencia del juego de las mismas diferencias. Y esto queda claro en la definición devenir:

«Lo que constituye la verdad no es ni el ser ni la nada, sino aquello que no traspasa sino que ha traspasado, vale decir el ser [traspasado] en la nada y la nada [traspasada] en el ser. Pero al mismo tiempo la verdad no es su indistinción, sino el que ellos no son lo mismo, sino que son absolutamente diferentes, pero son a la vez inseparados e inseparables e inmediatamente cada uno desaparece en su opuesto. Su verdad, pues, consiste en este movimiento del inmediato desaparecer de uno en otro: el devenir; un movimiento donde los dos son diferentes, pero por vía de una diferencia que al mismo tiempo se ha resuelto inmediatamente» ${ }^{30}$.

La muerte de Dios supone la emergencia de la multiplicidad, el fin de la metafísica de la unidad y el comienzo de un pensamiento débil, ya que una vez rechazada la verdad como validez única sólo queda la comprensión, la interpretación y el diálogo ${ }^{31}$. La diferencia también supone una actitud crítica ante cualquier

${ }^{28}$ G. W. F., Enciclopedia de las ciencias filosóficas, op. cit., pp. 190-191.

29 "[...] lo cierto es que el resultado final (aunque venga expresado de una forma "torcida") es el de la identidad de las diferencias entre lo diferenciado (el ser) y lo indeferenciado (la nada), y no el de la diferencia de la identidad y la no-identidad. Hegel piensa pues la diferencia desde la identidad, no al revés. Todavía no ha atravesado el pensamiento el desierto (más hórrido y espinoso que el del "reino de las sombras") del nihilismo. Lo Otro no deja de ser lo distinto de si-mismo. Desde esa Unidad piensa Hegel», F. Duque, Historia de la Filosofía Moderna. La era de la crítica, op. cit., p. 609.

30 G. W. F. Hegel, Ciencia de la Lógica, op. cit., pp. 77-78.

31 Sobre el nihilismo activo que responde a la muerte de Dios señala Diego Sánchez Meca: «La cultura occidental ha buscado el fundamento de la verdad y del bien en un mundo trascen- 
pensamiento que se sostenga afirmando la presencia con la intención de conseguir conciliaciones dialécticas, y en este caso la diferencia vendría a hermanarse con el concepto adorniano de dialéctica negativa ${ }^{32}$, ambos quiebran la identidad y, de ese modo, escapan del totalitarismo. En contraposición de la idea de diferencia que poseía la lógica hegeliana, el actual pensamiento de la diferencia acusa las discontinuidades para evitar la integración, y todo ello desde el nivel de la vida y no desde la conciencia idealista.

El pensamiento de la diferencia parece tener presente el olvido del ser que ha existido en la metafísica occidental. El olvido del ser ha favorecido a un desarrollo ontológico basado en una categorización del mundo y del ente que por una parte ha beneficiado al control objetivo de las cosas en un plano meramente técnico y productivo en el ámbito de una lógica social fundamentada en la producción constante sostenida e impulsada por una modernidad capitalista, y, por otra parte, en una falsa comprensión del hombre y de la vida de resultas de un sistema o método metafísico claramente constrictor hasta la asfixia para las realidades fluyentes de la vida, por lo demás no siempre sacadas a la luz debido a la importancia de lo irracional y de lo inconsciente en el hombre.

Temo, sin embargo, que en buena medida la crítica que se ha realizado en el último cuarto del pasado siglo a la filosofía clásica en los términos del pensamiento de la diferencia ponía en los textos kantianos y hegelianos, entre otros, implicaciones que aquellos no poseían en su historicidad ${ }^{33}$. Es decir, cuando

dente y absoluto, y ha puesto a Dios como garantía última de su existencia. Es cierto entonces que la "muerte de Dios" abre la perspectiva de un vacío, pero se trata de un desenlace que venía gestándose desde los comienzos de esta posición, pues se encontraba en germen en su propio planteamiento. La "muerte de Dios" no es un fenómeno de ateísmo que niega al Dios cristiano siguiendo una determinada lógica argumentativa. Es la conclusión de un proceso que abre, al fin, un horizonte nuevo y liberador, en la medida en que deja libres otras perspectivas para el conocimiento, la acción y la existencia misma», D. Sánchez Meca, El nihilismo, op. cit., p. 104.

32 Cfr. Th. W. Adorno, Dialéctica negativa, trad. de José María Ripalda, Madrid, Taurus, 1984.

33 «La situación histórica hace que la filosofía tenga su verdadero interés allí precisamente donde Hegel, de acuerdo con la tradición, proclamó su indiferencia en lo carente de concepto, en lo particular y especial, eso que desde Platón fue despachado como perecedero y sin importancia, para serle colgada al fin por Hegel la etiqueta de existencia corrompida. El tema de la filosofía serían las cualidades que ella misma degradó como contingentes a una quantité négligeable. Lo urgente para el concepto es aquello a lo que no llega, lo que el mecanismo de su abstracción elimina, lo que no es de antemano un caso de concepto», Theodor W. Adorno, Dialéctica negativa, op. cit., p. 16. 
leemos a Adorno exponer su dialéctica negativa, convenimos con su especulación al hilo de la experiencia del fanatismo totalitario que Europa vivió en la primera mitad del novecientos. Como he tratado de mostrar, en Hegel la diferencia posibilita el desarrollo mismo del sistema pero ella en sí no crea ninguna realidad efectiva, ésta se desarrolla a partir de la unidad. En nuestros días, rota la posibilidad de cualquier unidad acaso reste volver a descubrir la capacidad constructiva del intelecto a partir de las diferencias, incorporando en ese nuevo pensar los avances de una filosofía moral mucho más atenta a la existencia del otro.

\section{Bibliografía}

Adorno, Th. W. (1991). Tres estudios sobre Hegel, versión española de Víctor Sánchez de Zavala, Madrid, Taurus.

Adorno, Th. W. (1984). Dialéctica negativa, versión española de José María Ripalda, Madrid, Taurus.

DuQue, F. (1998). Historia de la Filosofia Moderna. La era de la crítica, Madrid, Akal.

Gabilondo, Á. (2001). La vuelta del otro. Diferencia, identidad y alteridad, Madrid, Trotta / Universidad Autónoma.

Hegel, G. W. F. (1974). Ciencia de la Lógica, trad. de Augusta y Rodolfo Mondolfo, Buenos Aires, Ediciones Solar.

- (2007). Fenomenología del Espiritu, estudio introductorio, traducción y notas de Manuel Jiménez Redondo, Valencia, Editorial Pre-textos.

- (2000). Enciclopedia de las ciencias filosóficas, ed., introd., y notas de Ramón Valls Plana, Madrid, Alianza.

- (2004). Lecciones sobre la Filosofía de la Historia Universal, versión de José Gaos, Madrid, Alianza.

Heidegger, M. (2006). La Fenomenología del Espiritu de Hegel. (Curso del semestre de invierno, Friburgo, 1930-1931), edición de Ingtraud Görland, traducción y notas de Manuel E. Vázquez y Klaus Wrehde, Madrid, Alianza Editorial.

KAnT, I. (2002). Critica de la razón pura, pról., trad., notas e índices de Pedro Ribas, Madrid, Alfaguara.

LOSEE, J. (2001). Introducción histórica a la filosofia de la ciencia, Madrid, Alianza. 
SÁnchez MeCA, D. (2001). Teoría del conocimiento, Madrid, Dykinson.

- (2004). El nihilismo. Perspectivas sobre la historia espiritual de Europa, Madrid, Síntesis.

SPINOZA, B. (1999). Ética demostrada según el orden geométrico, introd., trad., y notas de Vidal Peña, Madrid, Alianza.

Recibido: 19/01/2010

Aceptado: 21/06/2010 